\title{
Transvenous lead extraction of broken and abandoned azygos vein lead - case report
}

Damian Małecki 1,A-D,F, Witold Orszulak ${ }^{2, B}, K^{1,}$ Konrad Tomków ${ }^{3, B}$, Dorota Nowosielecka ${ }^{4, B}$, Łukasz Tułecki ${ }^{3, B}$, Marcin Grabowski ${ }^{1, A-B, D-F}$, Andrzej Wacław Kutarski ${ }^{5, A-B, D-F}$

A - Research concept and design, B - Collection and/or assembly of data, C - Data analysis and interpretation,

D - Writing the article, E - Critical revision of the article, F - Final approval of article

1 1st Department of Cardiology, Medical University of Warsaw

2 Ochojec Hospital, Katowice

3 Department of Cardiac Surgery, The Pope John Paul II Province Hospital of Zamosc Poland

4 Department of Cardiology, The Pope John Paul II Province Hospital of Zamosc

5 Department of Cardiology, Medical University of Lublin

Address for correspondence:

Damian Małecki, $1^{\text {st }}$ Department of Cardiology, Medical University of Warsaw email: dammalecki@gmail.com

Witold Orszulak, Ochojec Hospital, Katowice email: worszulak@poczta.onet.pl

Konrad Tomków, Department of Cardiac Surgery, The Pope John Paul II Province Hospital of Zamosc Poland email: konrad.tomkow@gmail.com

Dorota Nowosielecka, Department of Cardiology, The Pope John Paul II Province Hospital of Zamosc email: zdrowie@nowosieleccy.pl

Łukasz Tułecki, Department of Cardiac Surgery, The Pope John Paul II Province Hospital of Zamosc Poland email: luke27@poczta.onet.pl

Marcin Grabowski, $1^{\text {st }}$ Department of Cardiology, Medical University of Warsaw email: marcin.grabowski@wum.edu.pl

Andrzej Wacław Kutarski, Department of Cardiology, Medical University of Lublin email: a_kutarski@yahoo.com

Received: 2018-03-26

Revised: 2019-10-09

Accepted: 2019-10-09

Final review: 2018-11-18

DOI: $10.24255 / \mathrm{hbj} / 112927$

\section{Key words:}

transvenous lead extraction, lead damage, technical complications of TLE, azygos vein

\section{Introduction}

Technological progress in medicine allows us to help more patients with more complex diseases. Cardiology is no exception, with phenomenal progress of cardiac implantable electronic devices (CIED) throughout the last few decades. However, with the invention of new, more complicated CIED technologies, it becomes necessary to remove old systems. Removal of leads (especially those with a long dwell time) became a challenge that had to be overcome. Transvenous lead extraction (TLE) technique was developed to fulfil that need. Variable complexity of lead location, anatomical features and patients' conditions require that every TLE procedure must be prepared individually, with creativity and multiple tools needed in complicated cases.

\section{Case report}

A 44-year-old woman with hypertrophic cardiomyopathy (HCM) was admitted to an experienced TLE centre for azygos vein lead extraction. First an ICD as primary prophylaxis of sudden cardiac death was implanted in the left pectoral area sixteen years prior to the extraction procedure. The device was replaced after five years. Three years later, the ICD together with the lead was explanted due to CIED infection with endocarditis. A year later, the next ICD with a single coil lead was implanted contralaterally to the previous implantation side. A few incidents of ventricular tachycardia (VT) occurred during the service of the device, with a high defibrillation threshold (DFT) in every incident (specific data unavailable since the patient was referred from the cooperating institution 
that provided regular ICD control for the patient). The decision to upgrade the system with an azygos vein lead was made three years after implantation, but high DFT was maintained. Later that year, the system was upgraded to a high-energy ICD (St. Jude Medical) and the position of the ventricular lead was altered within the apex of the right ventricle, following the extraction of the previous ventricular lead. After two years the impedance of the azygos lead increased. The lead was suspected to be damaged and was turned off. A year later the device was replaced following the manufacturer's recall. Simultaneously, extraction of the damaged azygos lead was attempted, but a discontinuity was revealed (Figure 1) and the lead was abandoned.

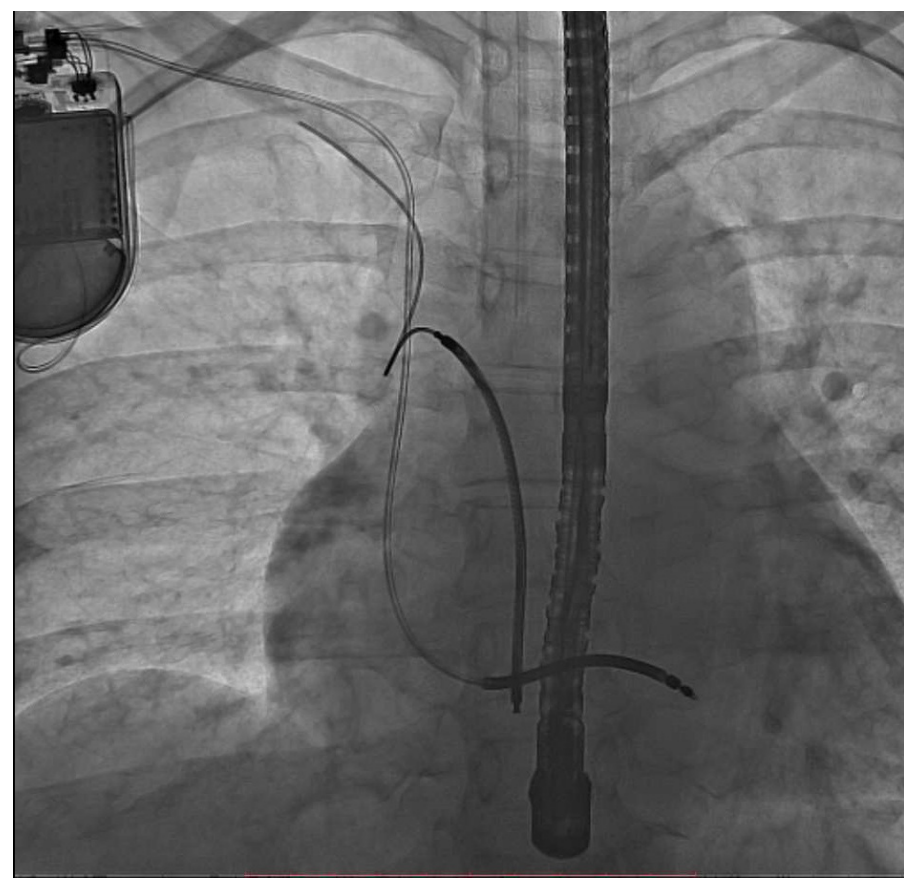

Figure 1.
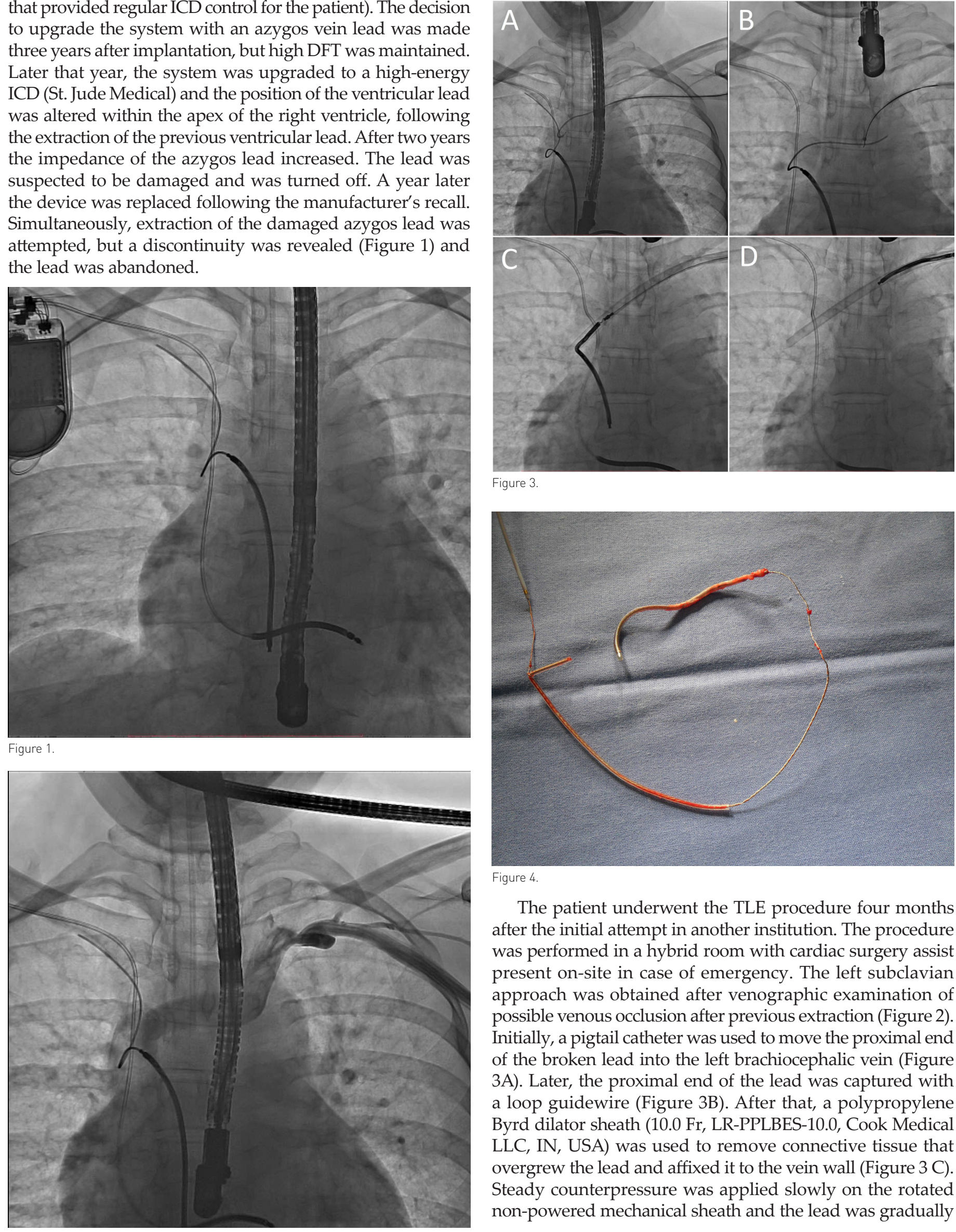

Figure 3 .

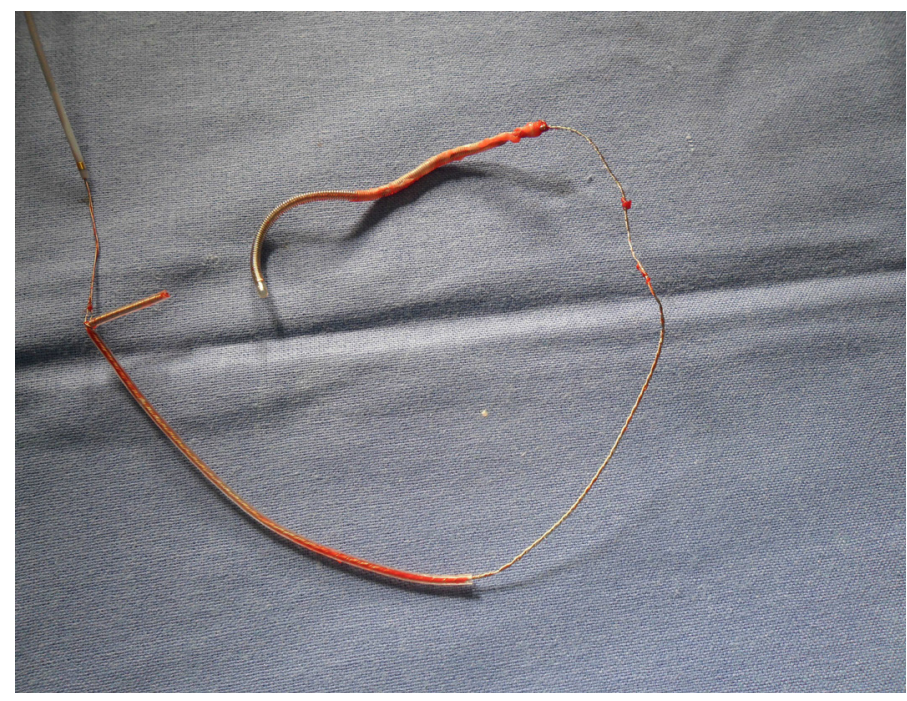

Figure 4.

The patient underwent the TLE procedure four months after the initial attempt in another institution. The procedure was performed in a hybrid room with cardiac surgery assist present on-site in case of emergency. The left subclavian approach was obtained after venographic examination of possible venous occlusion after previous extraction (Figure 2). Initially, a pigtail catheter was used to move the proximal end of the broken lead into the left brachiocephalic vein (Figure $3 \mathrm{~A})$. Later, the proximal end of the lead was captured with a loop guidewire (Figure 3B). After that, a polypropylene Byrd dilator sheath (10.0 Fr, LR-PPLBES-10.0, Cook Medical LLC, IN, USA) was used to remove connective tissue that overgrew the lead and affixed it to the vein wall (Figure $3 \mathrm{C}$ ). Steady counterpressure was applied slowly on the rotated non-powered mechanical sheath and the lead was gradually 
released from the adhesions. At the end, the freed lead was removed outside the body through the sheath (Figure 3D, 4). The postprocedural outcome was uncomplicated with good patient's condition.

\section{Discussion}

The patient had a complex previous history of ICD system management. After a few incidents of VT requiring high DFT, the decision was made to upgrade the device. A free-floating lead in the azygos vein was chosen to be added, for its location posteriorly to the heart, which is believed to improve performance of the system. Reposition of the right ventricle lead was also performed, it being a classic procedure to manage high $\mathrm{DFT}^{[1]}$. These actions, however, did not provide the expected DFT decrease. An upgrade to high-energy ICD was implemented and its outcome was satisfactory. Unfortunately, after a few years of service, an increase of azygos vein impedance was observed. Damage was the most likely cause and the lead was turned off. Soon after, the device's manufacturer announced the device's recall, and the patient underwent device replacement with a simultaneous attempt to remove the damaged lead. However, a discontinuity at the clavicle was revealed and only the proximal part of the lead was removed.

The fact that the lead was broken and with its proximal end in the cardiovascular system (CVS) predicted a more difficult and challenging TLE procedure ${ }^{[2]}$. The left subclavian approach was chosen with the internal jugular approach considered as the second choice, if the first one failed. The approach was chosen because of easier release of the adhesion on the right side, as well as lower possibility for infection of the existing system. The patient had suffered from ICD infection with endocarditis previously, with removal of the system implanted on the left side. Such history provided strong suspicion of left subclavian vein occlusion. Fortunately, no occlusion or stenosis was found and the procedure was performed from this approach. Firstly, the operator captured the proximal end of the lead. A polypropylene sheath was used to gradually 'cut out' the lead. Actions taken by the operator needed to be extremely precise and gentle, since any excessive pressure on the azygos vein could tear it up, resulting in excessive internal bleeding. Because of the unfavourable angle of the ostium, the operator's aim was to avoid using other extraction tools, for example a laser sheath. Use of such tools would increase the risk of vein damage and, therefore, major complications afterwards.

In this case, the procedure was characterised by high complexity and risk of major complications. Rare or atypical anatomical location of the extracted lead should be an indication for TLE in a high-volume centre.

\section{References}

1. Matassini MV, Healey JS; How to Manage a High Defibrillation Threshold in ICD Patients: and Does it Really Matter?; Curr Treat Options Cardiovasc Med. 2013 Aug;15(4):497-505

2. Kutarski A, Małecka B, Ząbek A, Pietura R; Broken leads with proximal endings in the cardiovascular system: serious consequences and extraction difficulties; Cardiol J. 2013;20(2):161-9 